\title{
Map Projection Education in Cartography Texibooks: A Content Analysis
}

The Pennsylvania State University

As developments in the field of map projections occur (e.g., the deriving of a new map projection), it would be reasonable to expect that those developments that are important from a teaching standpoint would be included in cartography textbooks. However, researchers have not examined whether map projection material presented in cartography textbooks is keeping pace with developments in the field and whether that material is important for cartography students to learn. To provide such an assessment, I present the results of a content analysis of projection material discussed in 24 cartography textbooks published during the twentieth and early twenty-first centuries. Results suggest that some material, such as projection properties, was discussed in all textbooks across the study period. Other material, such as methods used to illustrate distortion patterns, and the importance of datums, was either inconsistently presented or rarely mentioned. Comparing recent developments in projections to the results of the content analysis, I offer three recommendations that future cartography textbooks should follow when considering what projection material is important. First, textbooks should discuss the importance that defining a coordinate system has in the digital environment. Second, textbooks should summarize the results from experimental studies that provide insights into how map readers understand projections and how to choose appropriate map projections. Third, textbooks should review the impacts of technology on projections, such as the web Mercator projection, programming languages, and the challenges of projecting raster data.

KEYWORDS: map projection; datum; content analysis; cartographic education; history of cartography

\section{ACKNOWLEDGEMENTS}

I EXTEND THANKs to the three anonymous reviewers and Amy Griffin, the Editor of Cartographic Perspectives, for their helpful comments that improved this article. I also appreciate the help of Dr. Terry Slocum for his editorial assistance.

\section{INTRODUCTION}

While Developing A FORThComing book, Working with Map Projections: A Visual Guide to their Selection, I wanted to include an overview chapter on projections. This overview chapter is important, as my book is written for mapmakers with little background knowledge of the subject. To assist in determining appropriate projection material to include in this chapter, I arbitrarily sampled cartography textbooks published since 1990 and reviewed their contents, as these textbooks often contained overview chapters on projections. A casual inspection revealed considerable variation in the material they included. For example, one textbook explained in detail the steps needed to select a projection, while another provided no guidance. Further inquiry into textbooks written prior to World War II revealed that most placed emphasis on the technical skills needed to graphically construct projections. However, due to advancements in computer technology, these skills are no longer relevant and are not found in more recent textbooks. The variation in coverage that I found sparked my interest to more thoroughly examine what projection material was included in textbooks from 1900 to the present. 
This paper consists of three major sections. The first section summarizes the results of a content analysis of projection material presented in 24 cartography textbooks published during the twentieth and early twentry-first centuries, which were randomly selected from a larger set of textbooks, each containing a discussion of projections within a holistic discussion of mapmaking. The textbooks were published in English between 1900 and 2014. Briefly, the content analysis involved reading through each projection discussion and recording projection-specific words (e.g., "conformal"). These words were then used to create categories (e.g., map projection properties), and the categories were then used to characterize the projection material that was presented in the surveyed textbooks.

The second section discusses developments in the field of projections that took place during the twentieth and early twentry-first centuries, including new projections, methods of symbolizing distortion patterns, and applications of projections for specific map purposes. Some developments, such as programming languages, took place outside the field of projections, but were quickly integrated into the field during the latter half of this time period.

The third section ties together the results of the content analysis with these developments, with the ultimate goal of recommending what projection material should be included in future textbooks by summarizing earlier material and augmenting it with new developments that are significant for introductory students to learn. For example, viewing distortion across a projection's surface is obviously important for students to learn because of the differences between projections and their suitability for different mapping purposes. However, other developments may be important in a general sense but are not significant from a teaching standpoint. For instance, Lee's (1965) conformal map of the world in a triangle satisfied a specific mathematical curiosity, but does not have any practical cartographic advantage. Thus, learning about Lee's projection would not be particularly impactful from a teaching perspective.

\section{CONTENT ANALYSIS OF MAP PROJECTION MATERIAL IN CARTOGRAPHY TEXTBOOKS}

KrippendorfF (20I9) Divides content analysis into qualitative and quantitative approaches. Qualitative content analysis is concerned with drawing parallels between objects, whereas quantitative content analysis (which was utilized for this research) involves counting the frequency of objects or their attributes. Objects can include maps, images, written text, or verbal communication. The basic idea is to record the frequency of an object (e.g., counting the number of times the word "terrorist" appears throughout a series of newspapers) across a specific time period or particular media, gathering numerical data that can reveal patterns or themes. In return, these counts can be used to answer specific research questions (e.g., is the word "terrorist" used more frequently in newspapers since the events of 9/11?).

Content analysis has been applied in a variety of disciplines and provided insight into numerous cartographic research questions. Gilmartin (1992) used content analysis to contextualize 25 years of cartographic research appearing in three cartography journals. Using a combination of content analysis and focus groups, Monmonier and Gluck (1994) studied participants' views of animated cartographic software. Gluck (1998) applied content analysis as one of several qualitative techniques when investigating cartographic and geospatial images from the 1994 annual reports of 153 United States corporations. To examine the variation in map design across eleven editions of Goode's World Atlas, Muehlenhaus (2011) likewise employed it. I have previously (Kessler and Slocum 2011) used content analysis to examine map design in thematic maps published in the Annals of the Association of American Geographers and the Geographical Journal during the twentieth century. Most recently, Muehlenhaus (2013) administered the technique to evaluate the communicative characteristics of 256 persuasive maps.

Shreier (2012) outlines five steps that characterize a content analysis. She identifies the first step as the formulation of the research question. In the second, the researcher selects the appropriate material for the content analysis. The third step involves selecting the individuals who will perform the content analysis. During the fourth step, the categories that will be used to organize the data collected during the content analysis are defined. The fifth step rounds out the process by presenting and interpreting the 
findings of the content analysis. As shown in the following discussion, I applied these steps to carry out a content analysis of projection material in cartography textbooks from 1900 to 2014.

\section{STEP 1: IDENTIFY THE RESEARCH QUESTION}

One way that many students learn about projections is through cartography textbooks. Ideally, projection material included in these textbooks should keep pace with the developments in the broader mapping field. However, no studies exist that survey projection material included in these textbooks to determine if in fact students are being presented with material that will help them work with projections. This is the fundamental aim of this study.

\section{STEP 2: SELECTING THE MATERIAL FOR THE CONTENT ANALYSIS}

Selecting cartography textbooks for this study involved three substeps. In the first substep I reviewed sources to identify potential textbooks to include in the study. Fryman (1996) and Fryman and Sines (1990; 1998) listed cartography titles (mostly from the 1950s onward) that were adopted in university cartography courses. Examining bibliographies from textbooks published between 1940 and 1960 helped me to choose textbooks published between those decades. Finding textbooks older than 1940 (before cartography was accepted as a formal field of academic study), required searching for words like "mapping," "topography," or "surveying” in book titles. Keyword searches in online library catalogs (e.g., WorldCat) also provided assistance in identifying textbooks from throughout the study period. Since my primary language is English, I only considered English-language textbooks in this substep. At the conclusion, a total of 67 textbooks were identified as candidates to include in the study.

The second substep focused on examining each candidate textbook to see if the subject of projections was included. To be considered for this study, at a minimum, a candidate textbook had to contain at least some portion of a chapter or an appendix discussing projections. Textbooks on GIS, remote sensing, or projections tend to focus on methods of spatial analysis, satellite imagery, and the mathematical equations of projections, respectively, and were not included in this study. There were 48 textbooks that met the conditions of the second substep, listed in Appendix A.
The third substep used stratified random sampling from the 48 textbooks identified in substep 2; this was done to save time over conducting analysis on the entire group. I began the sampling by placing each of the 48 textbooks into the decade in which it was published. I then randomly sampled two textbooks from each decade. To avoid oversampling multiple editions of the same textbook, only one edition of each title was selected. Table 1 lists the 24 textbook titles, authors, and publication dates used for this study.

\section{STEP 3: CHOICE OF WHO PERFORMS THE CONTENT ANALYSIS}

An important methodological concern in content analysis is who performs the coding process. Schreier $(2012,34)$ explains that a content analysis should impart "objectivity and reliability," and thus multiple coders ideally should be employed. However, she offers that using one coder is possible, and that the coder can be the one doing the research. For example, Gilmartin (1992), Edney (2014), and Muehlenhaus (2011) each were the only coder in their own content analysis research. For this study I chose to be the coder for three reasons. First, I wrote three chapters on projections for Thematic Cartography and Geovisualization (Slocum et al. 2005). This was an invaluable experience that provided insight into how the subject of projections should be integrated into a cartography textbook. Second, I have taught a course on introductory cartography for twenty years. As the subject of projections has been an integral part of the course's lecture topics, I am aware of the struggles that students face when learning this subject. Third, I have researched and published material relevant to teaching projections such as how people comprehend distortion across a projection (e.g., Battersby and Kessler 2012).

Schreier $(2012,199)$ recommends that if a single coder is used, then one third of the material should be re-coded after a 10-14 day hiatus. Thus, I reexamined a random sample of eight of the 24 textbooks after a hiatus of 12 days; these are marked with an asterisk after the date in Table 1. After re-coding the eight textbooks and following the same methodology as outlined here, the results were consistent with the initial findings of the content analysis. 
Decade

Maps, Their Uses and Construction

Text Book of Topographical and Geographical Surveying

Maps and Map Making

1910

1930

1940

1950

1960

1970

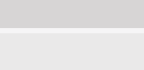

1980

Thematic Maps: Their Design and Practice

An Introduction to Mapwork and Practical Geography

Maps: Topographical and Statistical

Cartographic Methods

Map Use: Reading, Analysis, and Interpretation

Basic Cartography for Students and Teachers: Volume 1

Cartography: Thematic Map Design (2nd ed.)

1990

Introductory Cartography

Map Use and Analysis (5th edition)

2000

Thematic Cartography and Geovisualization (2 ${ }^{\text {nd }}$ ed.)

Cartography and Visualization of Spatial Data ( $3^{\text {rd }}$ ed.)

Principles of Map Design (2nd $e d$.)
Author(s)

Publication

Date

1902

James Morrison

$1905^{*}$

Charles Close

1910

Edward Reeves

1912

Herbert Wilson

1923

Arthur Hinks

$1924^{*}$

Lawrence Roberts

1936

Charles Deetz

Walter Jervis

$1937^{*}$

Helmuth Bay

1943

Erwin Raisz

$1948 *$

David Greenhood

$1951^{*}$

Arthur Robinson

1953

John Bygott and D. C. Money

$1962 *$

Thomas Birch

1964

George Lawrence

1971

Phillip Muehrcke and Juliana Muehrcke

1978

David Cuff and Mark Mattson

$1982 *$

Roger Anson and Ferjan

Ormeling

1984

Borden Dent

1990

John Campbell

1991

John Campbell

2005

Terry Slocum, Bob McMaster,

Fritz Kessler, and

$2005^{\star}$

Hugh Howard

Menno-Jan Kraak and Ferjan

Ormeling

2010

Judith Tyner

\section{4}

Table 1. The 24 cartography textbooks selected for this study. An asterisk after the date indicates that the textbook was used in the recoding process, as described in step 3 of the methodology. 


\section{STEP 4: DEVELOPING CATEGORIES TO ORGANIZE PROJECTION WORDS DURING THE CONTENT ANALYSIS}

Once the 24 textbooks were selected, I carefully read each projection section three times. During the first reading, I recorded descriptive data about each section that discussed projections, including the number of pages, illustrations, tables, and equations relating to projections. The second reading involved recording projection-specific words (e.g., "conformal," or an individual projection name). As a given projection word was encountered in a section, it was entered alphabetically into a single column in a spreadsheet (Figure 1). An additional column was included in this spreadsheet to record notes relating to the context in which the word was presented. For example, the term "sphere" could take on several different meanings depending on the context in which it was used. It could relate to the idealized form of Earth's shape, the stage of the projection process where Earth is conceptually reduced in size to the same scale as the final map, or an idealized mathematical figure. When the same term was presented in different contexts throughout a section, the word would be entered separately into the spreadsheet for each meaning, with a note explaining the context in which that term appeared. If a word was encountered whose relationship to projections was uncertain, the Glossary of Mapping, Charting, and Geodetic Terms (Department of Defense 1980) was consulted for a definition.

To create categories for the content analysis, the projection words entered into the spreadsheet during the second reading (Figure 1) were carefully examined, and those that shared similar concepts were combined together under an appropriate category name. For example, projection words like "latitude," "longitude," "great circles," and "small circles" characterize elements of the graticule, and so these words were combined into a category titled "Characterizing the Graticule." This process was repeated for all words from the spreadsheet, creating a total of ten categories, which are listed in Table 2 . The words that were used to develop the category names were then listed alphabetically under each category in a new spreadsheet (Figure 2). The top three rows in Figure 2 show the textbook title, author, and publication date, respectively. The left-hand column lists the category names (only Characterizing the Graticule category is shown in Figure 2) and the words that were used to develop the category name resulting from the second reading.

\begin{tabular}{|c|c|}
\hline Projection Word & Context Notes \\
\hline Airy's azimuthal & Projection name \\
\hline Albers equal area conic & Projection name \\
\hline Angles & Spatial relationship \\
\hline Arbitrary/ Conventional & Classification of projections \\
\hline Areas & Projection property \\
\hline Azimuthal & Projection property \\
\hline Azimuthal equidistant & Projection name \\
\hline Azimuths / Directions & Spatial relationship \\
\hline Bonne pseudoconic & Projection name \\
\hline Cassini's equidistant cylindric & Projection name \\
\hline Clarke's "Twilight" azimuthal & Projection name \\
\hline Co-latitude & \\
\hline Collingnon pseudocylindric & Projection name \\
\hline Compression & Distortion description \\
\hline Concentric circles & Graticule arrangement \\
\hline Cone & Developable surface \\
\hline
\end{tabular}

Figure 1. A portion of the spreadsheet showing the alphabetized listing of projection words and context notes from the second reading.

Data-Driven Map Projection Categories

Graphical Construction

Geodesy

Recommended Map Projections

Mathematics of Map Projections

Map Projection Parameters

Map Projection Process

Characterizing the Graticule

Map Projection Classes

Map Projection Properties

Map Projection Distortion

Table 2. Category names I developed for the content analysis, generated from individual projection-related words recorded from the 24 sampled textbooks. 


\begin{tabular}{|c|c|c|c|c|c|c|c|c|c|c|c|}
\hline Book Title $\rightarrow$ & $\begin{array}{c}\text { Text Book of } \\
\text { Topographical } \\
\text { and Geographical } \\
\text { Surveying }\end{array}$ & $\begin{array}{l}\text { Maps and } \\
\text { Map Making }\end{array}$ & $\begin{array}{l}\text { Topographic, trigonometric } \\
\text { and geodetic surveying, } \\
\text { including geographic, } \\
\text { exploratory, and military } \\
\text { mapping with hints on } \\
\text { camping, emergency } \\
\text { surgery, and photography }\end{array}$ & $\begin{array}{l}\text { Maps and } \\
\text { Surveys (2nd } \\
\text { ed) }\end{array}$ & $\begin{array}{l}\text { Topographic } \\
\text { Mapping }\end{array}$ & Cartography & $\begin{array}{l}\text { The World in } \\
\text { Maps: A } \\
\text { Study in Map } \\
\text { Evolution }\end{array}$ & $\begin{array}{l}\text { The History } \\
\text { and } \\
\text { Technique } \\
\text { of Map } \\
\text { Making }\end{array}$ & $\begin{array}{c}\text { General } \\
\text { Cartography } \\
\text { (2nd ed.) }\end{array}$ & Mapping & $\begin{array}{l}\text { Elements of } \\
\text { Cartography }\end{array}$ \\
\hline Author $\rightarrow$ & Charles Close & $\begin{array}{l}\text { Edward } \\
\text { Reeves }\end{array}$ & Herbert Wilson & Arthur Hinks & $\begin{array}{l}\text { Lawrence } \\
\text { Roberts }\end{array}$ & Charles Deetz & Walter Jervis & $\begin{array}{l}\text { Helmuth } \\
\text { Bay }\end{array}$ & Erwin Raisz & $\begin{array}{l}\text { David } \\
\text { Greenhood }\end{array}$ & $\begin{array}{l}\text { Arthur } \\
\text { Robinson }\end{array}$ \\
\hline Publication Date $\rightarrow$ & 1905 & 1910 & 1912 & 1923 & 1924 & 1936 & 1937 & 1943 & 1948 & 1951 & 1953 \\
\hline & & & & & & & & & & & \\
\hline & & & & & & & & & & & \\
\hline Characterizing the Graticule & 1 & 1 & 1 & 1 & 1 & 1 & 1 & 1 & 1 & 1 & 1 \\
\hline Network (Imaginary) & & & 1 & 1 & & 1 & & & & & \\
\hline Graticule / Grid & 1 & & & & & & 1 & & 1 & 1 & 1 \\
\hline Degree-net & & & 1 & 1 & & & & & & & \\
\hline The graticule & 1 & & 1 & 1 & & 1 & 1 & & 1 & 1 & 1 \\
\hline Visual characteristics of the graticule & & 1 & 1 & 1 & & & & & & & 1 \\
\hline $\begin{array}{c}\text { Descriptions of a projection's } \\
\text { graticule }\end{array}$ & 1 & 1 & 1 & 1 & 1 & 1 & 1 & & & 1 & 1 \\
\hline $\begin{array}{l}\text { Almucantars (parallel circles from the } \\
\text { center) }\end{array}$ & & & & & & 1 & & & & & \\
\hline Antipode & & & & & & & & & & & 1 \\
\hline Compass Rose & & & & & & 1 & & & & & 1 \\
\hline & & & & & & & & & & & \\
\hline Gore (lune shaped) & & & & & & & & & & 1 & \\
\hline Latitude & & 1 & 1 & 1 & 1 & 1 & 1 & & 1 & 1 & 1 \\
\hline Parallel & 1 & 1 & 1 & 1 & 1 & 1 & 1 & & 1 & 1 & 1 \\
\hline Small circle & & & & & & 1 & & & 1 & 1 & 1 \\
\hline Orthodrome & & & & & & & & & & & \\
\hline Equator & & & 1 & & 1 & & 1 & & 1 & 1 & 1 \\
\hline Circumscribing circle & & & & & & & & & & & \\
\hline Large (Great Circle) & & 1 & & 1 & & 1 & & 1 & 1 & 1 & 1 \\
\hline Longitude & & 1 & 1 & 1 & 1 & 1 & & & 1 & 1 & 1 \\
\hline Meridian & 1 & 1 & 1 & 1 & 1 & 1 & 1 & & 1 & 1 & 1 \\
\hline Prime meridian & & & & & & & 1 & & 1 & 1 & 1 \\
\hline $\begin{array}{c}\text { International Date Line }\left(180^{\circ} \text { th }\right. \\
\text { Meridian) }\end{array}$ & & & & & & & & & 1 & & \\
\hline Antimeridian & & & & & & & & & & & \\
\hline
\end{tabular}

Figure 2. A portion of the spreadsheet displaying the occurrence of projection words in the Characterizing the Graticule category, according to each textbook.

Once the ten categories were developed, the third reading involved reexamining each projection section and recording the occurrence of projection words that appeared in each textbook for a given category. Projection words that appeared in a given textbook were assigned a value of 1 in the spreadsheet (Figure 2) according to the category in which the word belonged. For example, if a textbook used the word "antipode" a value of 1 was coded in the spreadsheet as that word related to the Characterizing the Graticule category. Not all assignments of 1 were clear-cut. For example, as I mentioned earlier, textbooks used the word "sphere" in one of three different contexts: one for Earth's assumed shape (Geodesy category), the idealized mathematical figure (Mathematics of Map Projections category), and as an intermediate step during the projection process (Map Projection Process category). Thus, it was important to pay attention to the context in which the word was used so that a proper assignment of 1 was recorded.

\section{STEP 5: REPORTING AND INTERPRETING THE RESULTS}

\section{Descriptive Data}

Of the 24 textbooks sampled, six presented projection material as a portion of a chapter, eight did so within exactly one chapter, two used an appendix, and eight dedicated more than one chapter. The total number of pages used to present projection information ranged from 151 (Morrison 1902) to only a few paragraphs (Lawrence 1971). Most of the textbooks were richly illustrated with individual projections. There were five textbooks that included more than 50 illustrations, the largest number being 61 (Slocum et al., 2005). Four textbooks included fewer than 10 illustrations: Deetz (1936) showed only three while Roberts (1924), Jervis (1937), and Bay (1943) did not include any. All of the illustrations were produced in black and white. The inclusion of equations and tables was dichotomoustextbooks either had many equations and tables or none. Generally speaking, if a textbook included equations, then 
those equations expressed the spherical form rather than the ellipsoidal form of projections. Textbooks early in the study period tended to have a greater number of equations than those later in the study period. These equations were essential as they provided the mathematics of how to graphically construct projections. Thirteen of the textbooks throughout the study period did not include any equations. Similar to equations, tables were more often found in textbooks that were published earlier in the study period. In early textbooks, tables often listed the plotting coordinate values needed for the graphical construction of projections. Other tables presented values showing the length of a degree of latitude and longitude.

All textbooks included a definition of the term "projection" and there was general agreement about what that definition entailed. For example, Close $(1905,92)$ defined a projection as a "system on which the terrestrial meridians and parallels are represented on paper." This and the other definitions collectively agreed that a projection systematically transforms points from Earth's curved surface to the plane.

\section{Categories Derived from Content Analysis}

This section discusses the individual categories of projection words derived from the content analysis. The discussion highlights the percentage of textbooks that contain each category and summarizes the specific projection-related words contained in each textbook. Recognizing the large expanse of time covered by the twentieth and early twentry-first centuries, I sought a way to divide this time period into a temporal framework that would facilitate reporting the results of the content analysis. One way to divide this period is to consider the impact of the computer on the field of cartography, specifically within the realm of projections. I have previously used this approach

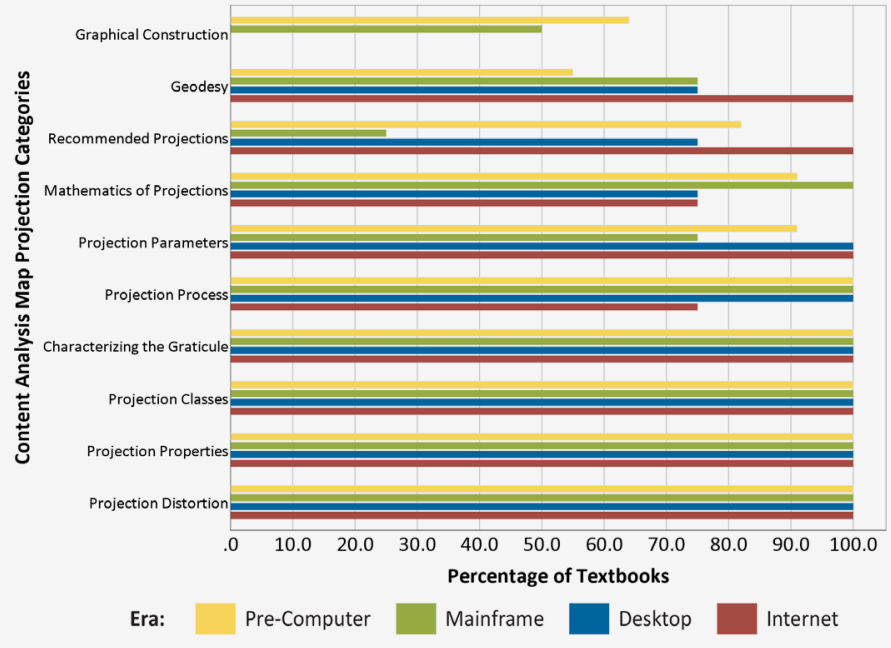

Figure 3. Percentage of textbooks that contain words related to the different categories reported by individual eras.

(Slocum and Kessler 2015), dividing the twentieth and early twentry-first centuries into four separate eras demarcated by the onset and evolution of computing technology: Pre-Computer Era (1900-1958), Mainframe Computer Era (1959-1976), Desktop Computer Era (1977-1990), and Internet Era (1991 onward). Using these four eras, the results of the content analysis are summarized in Figures 3 and 4 . Figure 3 provides the percentages of textbooks containing words from each map projection category found in each individual era and Figure 4 reports the percentages of textbooks containing words from each map projection category for all eras combined.

\section{Graphical Construction Category}

The Graphical Construction category refers to a process by which concepts of plane geometry were used to draw curves and partition straight lines representing the graticule on paper. Thirty-nine percent of textbooks across all eras included the Graphical Construction category.

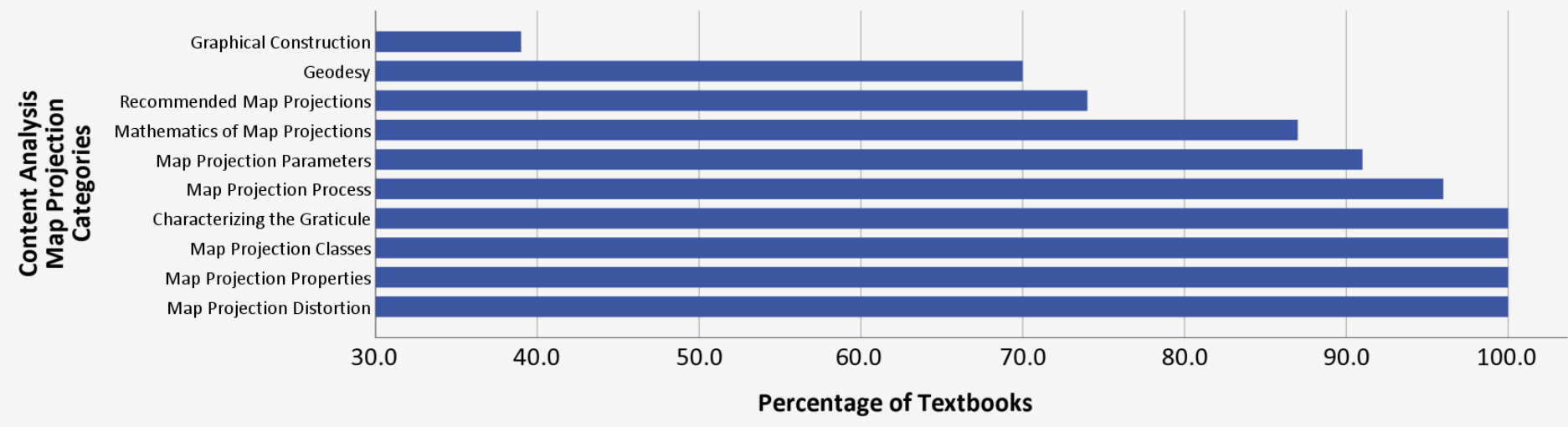

Figure 4. Percentage of textbooks that contain words related to the different categories across all eras. 
However, Figure 3 shows that this category was only relevant to the Pre-Computer and Mainframe Computer eras. Once desktop computers became widely accessible, this category became irrelevant.

\section{Geodesy}

The Geodesy category included words that describe Earth's shape and size. Seventy percent of all textbooks included words that relate to geodesy (Figure 4). Figure 5 shows the percentage of textbooks that included the three most common words in this category across each era: "reference ellipsoid," "semi-major axis," and "sphere." Overall, $43 \%$ of the textbooks contained all three of these words, with all words occurring more frequently in the two most recent eras.

The reference ellipsoid is an important concept when making accurate, large-scale maps of the Earth's surface (e.g., in topographic mapping) while other maps, such as thematic or general reference maps, typically do not have the same accuracy requirements. In the Pre-Computer Era, considerable effort was needed to incorporate a reference ellipsoid when making maps. Beginning with the Mainframe Computer Era, cartographers started using digital data where coordinate system definitions and automation allowed the reference ellipsoid to be seamlessly integrated into the mapping process, thus reducing the cartographer's effort. In this context, it is interesting to see that the percentage of textbooks that included "reference ellipsoid" as part of the discussion increased from 18\% in the Pre-Computer Era, to 50\% in the Mainframe Era, and to $75 \%$ for the Desktop Computer and Internet Eras.

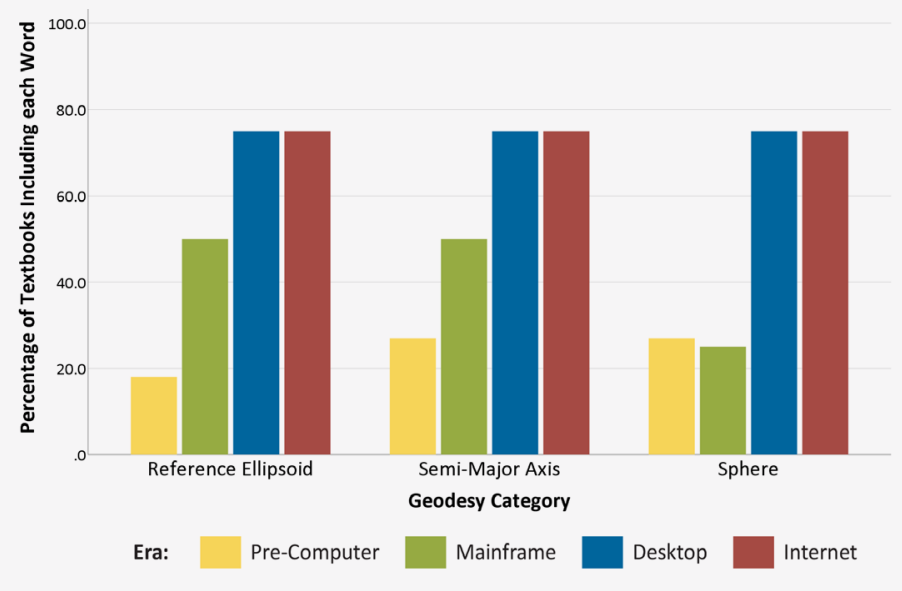

Figure 5. Percentage of textbooks containing the three most common words within the Geodesy category, according to individual eras.
This growth seems consistent with the increasing reliance on digital data as time evolved.

\section{Recommended Map Projections}

The Recommended Map Projections category indicated which textbooks recommended certain projections for particular map purposes. This category also included guidelines related to selecting an appropriate projection. In total, 55 unique projections were recommended by the 24 textbooks studied. Figure 4 shows that $74 \%$ of textbooks across all eras recommended one or more projections, and Figure 3 indicates that the Pre-Computer Era and Internet Era saw the greatest number of textbooks recommending projections at $82 \%$ and $100 \%$, respectively. Figure 6 shows the projections that were recommended most frequently across all eras. The azimuthal equidistant, Lambert azimuthal equal area, Mercator, and sinusoidal were popularly recommended in every era.

Aside from recommending certain projections, a total of 12 textbooks across all eras also included guidelines that linked individual projections to specific map purposes. Guidelines on selecting projections appeared in $45 \%, 25 \%$, $75 \%$, and $75 \%$ of the textbooks in the Pre-Computer, Mainframe Computer, Desktop Computer, and Internet Eras, respectively. Generally speaking, textbooks offered selection guidelines that could be classified as either very simple or detailed. The simplified selection guidelines (found in $25 \%$ of the 12 textbooks with guidelines) indicated, for example, that conic projections are suitable for east to west trending landmasses or that equal area projections are appropriate for thematic maps. The detailed guidelines worked through the selection process using a sample dataset and ultimately recommended a specific named projection. For example, a detailed approach in the Pre-Computer Era appeared in Deetz (1936) who

\begin{tabular}{|c|c|c|c|c|}
\hline Projection Name & $\begin{array}{c}\text { Pre-Computer } \\
\text { Era }\end{array}$ & $\begin{array}{c}\text { Mainframe } \\
\text { Computer } \\
\text { Era }\end{array}$ & $\begin{array}{c}\text { Desktop } \\
\text { Computer } \\
\text { Era }\end{array}$ & Internet Era \\
\hline Azimuthal equidistant & & & & \\
\hline Lambert azimuthal equidistant & & & & \\
\hline Mercator & & & & \\
\hline Sinusoidal & & & & \\
\hline Albers equal area conic & & & & \\
\hline Lambert conformal conic & & & & \\
\hline Orthographic & & & & \\
\hline Bonne & & & & \\
\hline Polyconic & & & & \\
\hline Stereographic & & & & \\
\hline
\end{tabular}

Figure 6. The most frequently recommended projections in textbooks, according to individual eras. 
discussed the appropriateness of 15 projections. His guideline discussed each projection's graticule arrangement, the projection's property, whether the projection possessed any special characteristic, and the utility of the projection. The detailed selection guidelines were more often found in the Desktop Computer and Internet Eras. For example, in the Desktop Computer Era, Dent (1990) created tables that recommended specific projections based on various criteria, such as the extent of the geographic region to be mapped. In the Internet Era, comprehensive selection guidelines were presented by Slocum et al. (2005) who devoted an entire chapter to selecting projections. They framed their chapter on Snyder's (1985) projection selection guidelines and then used that framework to explain how a suitable projection was determined based on different data sets, geographic areas to be mapped, map scales, and map purposes.

\section{Mathematics of Map Projections}

The Mathematics of Map Projections category included 27 words that relate to explaining the mathematical principles used in the projection process. In total, $87 \%$ of textbooks utilized one or more of these words. Figure 3 shows the percentage of textbooks that included this category in each of the four eras, while Figure 7 shows the percentage of textbooks that included the three most common words in this category across each era: "cosine of latitude," "rectangular coordinates (Cartesian)," and "sphere." The Pre-Computer Era reported the greatest variety of and the greatest overall frequency of mathematical words. In addition to the three previously mentioned most common words, others like "sine of the latitude," "cone constant,"

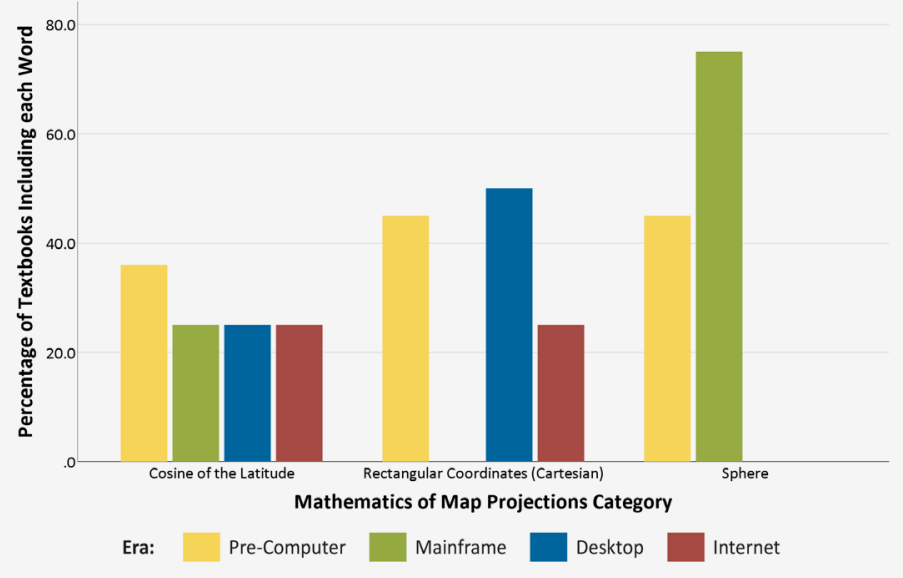

Figure 7. Percentage of textbooks containing the three most commonly found words within the Mathematics of Map Projections category, according to individual eras. and "radius of curvature" were more frequent in this era than in other eras. This occurrence seems reasonable as these words are directly related to the process of graphically constructing projections, which dominated this era.

\section{Map Projection Parameters}

The Map Projection Parameters category refers to the variables that mapmakers manipulate to change the appearance or distortion patterns of a projection (e.g., which standard lines are utilized). This category appeared in $91 \%$ of all of the textbooks (Figure 4) and 24 unique words were recorded. Considering all eras, only two texts, Jervis (1937) and Birch (1964), did not include any words related to discussing projection parameters. The most frequently occurring projection parameter word across all eras was "standard parallel(s)" or "standard line(s)," found in $63 \%, 75 \%, 100 \%$, and $100 \%$ of the textbooks in the PreComputer, Mainframe Computer, Desktop, and Internet Eras, respectively. Words relating to a projection's aspect, such as "normal," "polar," and "equatorial," also appeared in almost every textbook across the different eras. Interestingly, the specific words associated with "normal aspect" saw considerable variation across the eras. For example, normal aspect was often defined according to the typical aspect in which a projection was shown (e.g., an azimuthal projection was typically shown as centered on a pole whereas a cylindric projection was typically shown as aligned along the Equator). Thus, "normal aspect" was not consistently applied to one particular aspect but was dependent upon the projection class and could be easily misunderstood unless the reader knew the particular projection class being referenced.

\section{Map Projection Process}

The Map Projection Process category refers to the steps involved in projecting Earth's curved surface to the map. Words relating to this category were found in 22 of the textbooks, with 30 unique words being recorded. In total, $96 \%$ of the textbooks included words relating to this category (Figure 4). Given this high percentage, there was little difference in the frequency of word usage across the eras when explaining the projection process. The most frequently occurring words across all eras included "developable surface," "tangent," "cone," "cylinder," and "plane." Other words such as "light bulb," "light source," "eye-point," "point of sight," "radiating," "rays of light," and "peel off" were mnemonic devices that described how the graticule was projected onto the planimetric surface, 
although none of these words were found in more than two textbooks in any given era.

\section{Characterizing the Graticule}

The Characterizing the Graticule category included any term that was used to characterize the graticule's appearance on a map. Every textbook used one or more words to characterize the graticule, and a total of 37 unique words were utilized. There was little variation in the use of these words across the different eras. Figure 8 shows the seven most frequently appearing words in this category across all eras. Of interest is that "parallel" or "latitude" was included more than "meridian" or "longitude," which is not surprising given that many spatial phenomena studied in geography have one or more characteristics that vary only according to latitude.

\section{Map Projection Classes}

The Map Projection Classes category included words that relate to one of the projection classes (e.g., "cylindric," "conic," "azimuthal," and "pseudocylindric"), which are used to describe the overall visual shape and appearance of the graticule. This category was found in all of the textbooks throughout the different eras (Figure 4), with 20 unique words being recorded. The "conic" (87\%) class was referenced more frequently than either the "cylindric" (83\%) or "azimuthal" (61\%) classes across all eras. Not all classes appeared in some of the eras. For example, "pseudoazimuthal" and "pseudoconic" were not reported until the Desktop Computer Era. As another example, it was noted that "geometric" and "conventional" were important terms used during the Pre-Computer Era to refer to the methods of constructing projections graphically and mathematically, respectively. These terms were also used to classify projections. Given that graphical construction techniques have not appeared in textbooks since the 1960s, it is somewhat surprising to see these words included in textbooks published during the Mainframe Computer, Desktop Computer, and Internet Eras.

\section{Map Projection Properties}

The Map Projection Properties category focused on words related to the projection properties (e.g., "equal area," "conformal," "equidistance," and "azimuthal"). A projection with one of these properties will preserve one of the spatial relationships found on Earth's surface, such as distances or areas. This category was found in $100 \%$ of the

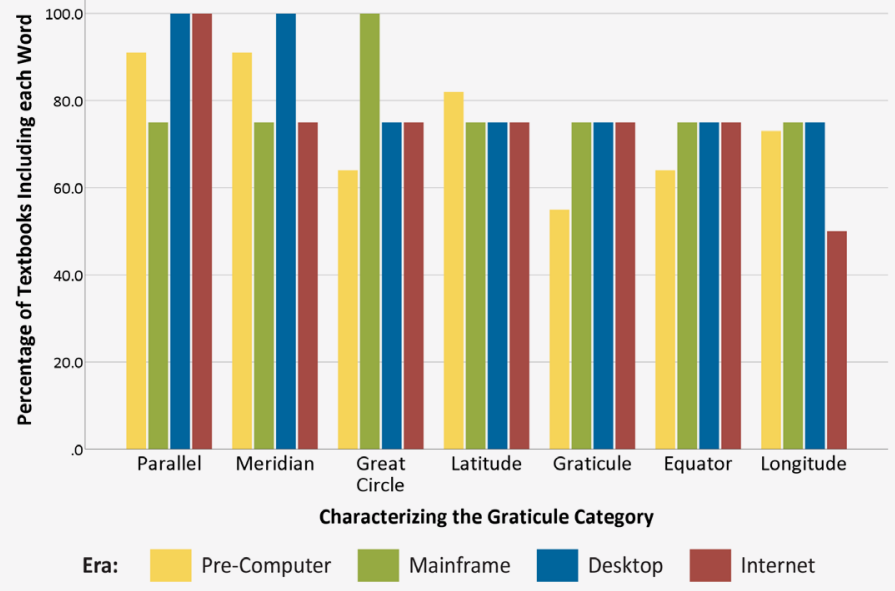

Figure 8. Percentage of textbooks containing the most common words from the Characterizing the Graticule category, according to individual eras.

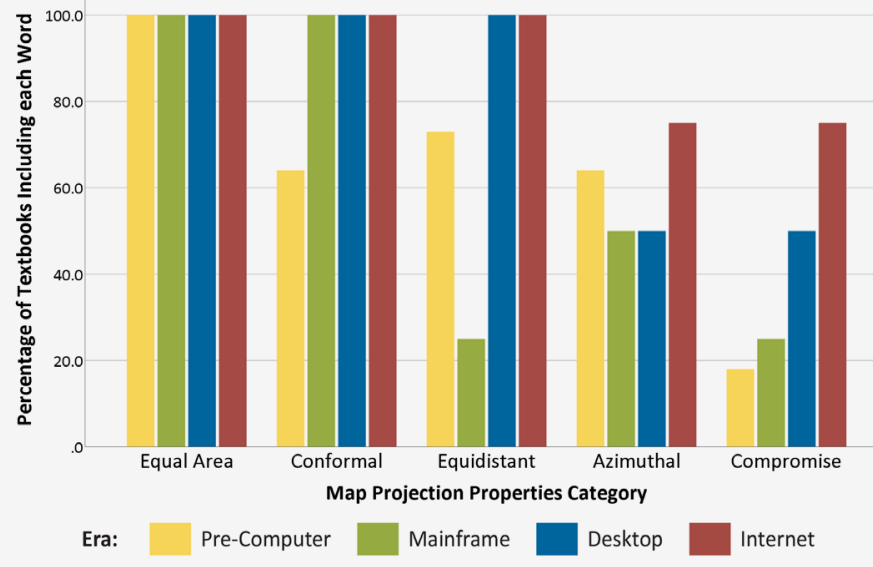

Figure 9. Percentage of textbooks that contained the three most common words from the Map Projection Properties category, according to individual eras.

textbooks (Figure 3), with 27 unique words being recorded. Figure 9 shows the percentage of textbooks that included the five most frequently appearing words across all eras: "Equal area," "conformal," "equidistant," "azimuthal," and "compromise." Across all eras, "equal area" (and its synonym "equivalent") was reported in every textbook. The frequency of this term is consistent with the fact that the textbooks included in this survey tended to focus on thematic mapping, in which equal area projections are often appropriate. Another common term was "conformal" (and its synonym "orthomorphic"), which was found in $91 \%$ of the textbooks in the Pre-Computer Era and all of the textbooks in the remaining eras. Generally, the remaining properties of "equidistant," "azimuthal," and "compromise" were more common in the two most recent eras. 


\section{Map Projection Distortion}

The Map Projection Distortion category focused on the fact that Earth's curved surface cannot be projected without error, that the error can be quantified according to the type of distortion (areal, angular, or scale), and that this result can be graphically portrayed on a map. Figure 3 illustrates that $100 \%$ of the textbooks sampled throughout the four eras discussed projection "distortion." Specific words commonly utilized with distortion are, "area," "angular," "scale," and "shape," these were referenced in 96\%, $82 \%, 65 \%$, and $50 \%$ of textbooks, respectively, across all eras. Words used to conceptualize distortion included "peeling skin off of fruit," "squashed," "stretched," "exaggeration," "flattening a ball," and "compressing." These and other words relating to distortion were not consistently adopted as they all appeared in two or fewer textbooks and did not span the four eras.

While it is not likely that cartography students will need to understand the mathematics of deriving distortion measures, being able to visualize distortion across a projection's surface is important (e.g., to select an appropriate projection). Distortion visualization has had a rather long history of development. An early graphical method for viewing distortion across a projection's surface is Tissot's (1859) indicatrix, which presents a visual impression of the type and amount of distortion at any given point. The first reference in my study to utilize Tissot's indicatrix was Robinson (1953). Reference to the indicatrix concept would not appear again until the Desktop Computer Era when Cuff and Mattson (1982) and Anson, Ormeling, and the ICA (1993) used the phrase "ellipse of distortion" to refer to Tissot's indicatrix. In the same era, Dent (1990) discussed the concept of the indicatrix, but did not illustrate the graphic on a projection. Also in this era, Campbell (1984) reported what appears to be the indicatrix, but the concept was confounded by the suggestion that the axes of the symbols only represent scale changes along the parallels and meridians, which is not the case. In the Internet Era, Slocum et al. (2005) and Tyner (2014) included "indicatrix" in their discussion.

A range of other graphical methods were used to illustrate distortion on projections (see Mulcahy and Clarke 2001, for a summary of methods). For example, Reeves (1910) showed a series of human head profiles to illustrate the effect of distortion on different projections. Robinson (1953) illustrated distortion with isocols, which were synonymously referred to as "isoanamorphic lines," "isoperimetric curves," and "isograms." Anson, Ormeling, and the ICA (1993) presented distortion on a projection with shading between adjacent isocols. Dent (1990) included the words "tearing," "compression," and "shearing" in an illustration to point out the changes to the graticule that can result from a projection. He also showed how a square shape was distorted across the sinusoidal projection, mentioning that it is at the periphery of the projection where shapes are most distorted. Slocum et al. (2005) used a combination of the indicatrix and shaded isocols to illustrate distortion. Overall, none of the graphical methods used to display distortion appeared more frequently than others over the time period of the study.

\section{DEVELOPMENTS IN THE FIELD OF MAP PROJECTIONS}

THIS SECTION BRIEFLY DISCUSSES developments that occurred during the twentieth and early twentry-first centuries that impacted the field of projections. This discussion, coupled with the results of the content analysis, will be integrated in the next section to provide recommendations on appropriate projection material that should be included in future cartography textbooks. I argue that there were three specific developments that impacted projections. First, computer technology was developed, which fundamentally changed the way projections were integrated into the mapmaking process. Second, experimental studies were conducted that investigated various aspects of a map reader's understanding of projections. Third, advanced mathematical principles were applied to the field, which resulted in a refinement of existing projections that could be included in specialized mapping software.

\section{ADVANCEMENTS IN COMPUTER TECHNOLOGY}

This section discusses three impacts that computer technology had on the field of projections. First, the development of computer technology in the twentieth century removed much of the manual burden of working with projections that was common in the Pre-Computer Era. Starting in the Mainframe Computer Era, automation in cartography, 
specifically programming languages, facilitated the ability to calculate and plot projections. Programming languages also enabled specialized mapping software (e.g., desktop GIS) to emerge in the Desktop Computer Era, which provided users with access to a diversity of pre-existing projections. For example, ARC/INFO version 6.0 provided the user with 34 named projections (Esri 1991). Two notable projection software packages that emerged during the Desktop Computer Era were WORLD (a DOS-based program) and Geocart (a Mac-based program); both packages enabled users to plot isocols or Tissot's indicatrix on a projection's surface. In the Internet Era, Geocart version 3.0 enabled users to depict increasing amounts of distortion with a continuous tone of light to dark color values (Figure 10). Armed with the visualizations provided by these graphical methods, mapmakers were able to make better informed decisions about which projection was best suited to their purpose.

A second impact of computer technology is that digital data need a coordinate system definition, which allows the alignment of individual data layers. At a minimum, this definition involves specifying a datum and its associated reference ellipsoid. In addition, a projection can be selected. The datum and projection each serve a specific function. For example, Chrisman (2016) argued that certain measurements carried out in a GIS environment (e.g., distances) should always be computed on a datum's reference ellipsoid, as those measurements are not subjected to the distortion that would be introduced by a projection. However, datums are not suitable for mapping the results of a spatial analysis as a datum reports latitude and longitude values. An appropriate projection must be selected that meets the needs of a specific map purpose (e.g.,

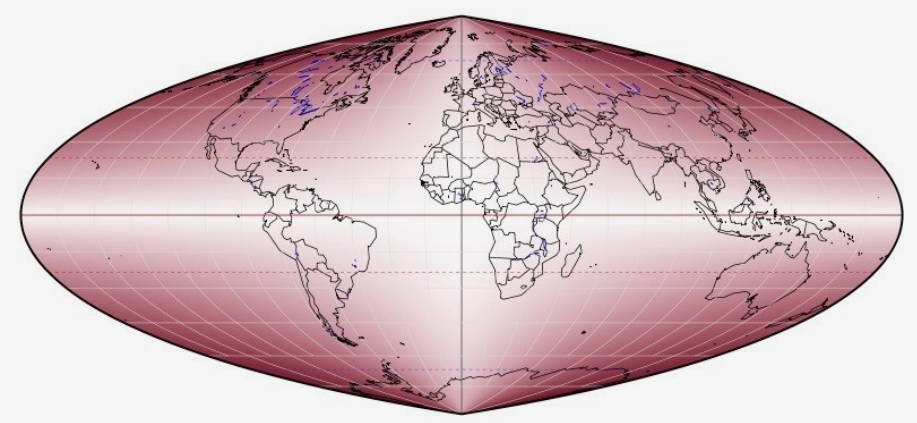

Figure 10. Darker colors represent increasing angular distortion on the quartic authalic pseudocylindric projection. Color gradations were available in Geocart starting in 2010. Image created in Geocart (www.mapthematics.com). preserving areal relations for a choropleth map). Therefore, mapmakers have increasingly needed to become familiar with the roles that datums (and their associated reference ellipsoids) and projections play when working with digital data.

The third impact can be seen in the interactive nature of the World Wide Web, which has facilitated the ability to explore different kinds of projections and their associated distortion patterns. For example, Lapaine, Tutić, and Triplat (2014) published a freely available tool that permits users to explore different cylindric projections, their graticule arrangements, and their distortion patterns. The web also made new uses of projections. Particularly noteworthy is the web Mercator, which is utilized in mapping services such as Google Maps. A non-conformal projection, the web Mercator is derived by forcing the ellipsoidal form of latitude and longitude coordinates through a spherical form of the Mercator cylindric conformal projection equations (Battersby et al. 2014).

\section{EXPERIMENTAL STUDIES}

Until shortly after World War II, few experimental studies set forth to understand how people perceived or reacted to different map designs. In short, mapmakers were working with little knowledge of how the maps were being used or understood by readers. Although not the first to do so, Robinson's landmark text The Look of Maps (1952) proposed a research agenda to understand map design; this agenda eventually morphed into cognitive cartographic studies, which are still being conducted today (Montello 2002). While the Look of Maps did not specifically call for experimental studies to be carried out with respect to projections, cartographers have investigated how projections play a role in map design and are understood by the map reader.

Dahlberg (1991) suggested that understanding map readers' preferences for overall shapes of projections should be considered as a variable in map design when selecting a projection, especially for global-scale maps. For example, we might wonder whether readers prefer maps whose graticule mimics the globe's appearance, with curved meridians and parallels. In this context, studies by Werner (1993) and Šavrič et al. (2015) examined preferences for overall projection shapes at global scales. Werner's study suggested that pseudocylindric projections were preferable to cylindric, and uninterrupted pseudocylindric projections 
were favored over interrupted ones. Šavrič et al. also found that map readers liked smooth, elliptical rather than sinusoidal curves for meridians, straight rather than curved lines for parallels, and poles represented as points, but that map readers had no preference for pole line edges.

How map readers reconcile projection distortions with their mental maps is another line of experimental studies. Battersby and Montello (2009) investigated whether map readers' mental maps of the world were overly influenced by the Mercator projection. Their results suggested that map readers were rather competent in estimating relative areas of landmasses and that they were not relying upon a mental map based on a Mercator or Mercator-like projection. With colleague Sarah Battersby, I have also previously explored (Battersby and Kessler 2012) how map readers visualize distortion on projections. One finding from our study is that map readers favored one of three regions (Antarctica, Greenland, and the polar regions) as cues in assessing the distortion on a projection and that training or expertise with projections does not necessarily provide map readers with a skillset necessary for understanding distortion.

Research by Downs and Liben (1991) examined drawings and mnemonic devices, which have often appeared in cartography textbooks to illustrate projection concepts (e.g., a light source casting shadows on a developable surface). Their findings suggested that what may be intuitive to an expert geographer may not be self-evident to map readers. They concluded that the commonly used mnemonic device of the light-source casting a shadow on a cone, cylinder, or plane developable surface does not necessarily help all map readers understand how Earth's curved surface is projected onto a map. As a solution to this problem, they suggested having map readers develop an understanding of light sources and shadows using extremely simple shapes, and then gradually move toward more complex shapes (such as a landmass).

Experimenters have also studied the spatial abilities of readers when using projections to solve map-based tasks. One study, conducted by Anderson and Leinhardt (2002), examined the difficulty that map readers face when applying rules that work on a sphere (e.g., extending a "straight" line on a globe eventually returns to itself) to a plane when considering the influence of projection distortion. Their study contrasted the abilities of domain experts, advanced novices, pre-service teachers, and novices to construct a path of shortest distance (or great circle) between pairs of cities on a map. They found that experts were able to perform the tasks significantly better than the other groups and that advanced novices performed better than the novices or pre-service teachers. They reasoned that the experts and advanced novices understand how projections distort Earth-map relationships and specifically how the Mercator projection distorts great circles. Thus experts and advanced novices were able to use existing rules of how lines appear on a sphere to generate advanced visualizations to arrive at a solution for a plane. Novices and pre-service teachers did not have advanced rules, could not create serviceable visualizations of the problem, and thus generally guessed at their solutions.

\section{ADVANCED MATHEMATICAL PRINCIPLES}

As Snyder (1993) recounts, the 1700s and 1800s were important times in the development of more advanced mathematical principles. Least squares, calculus, complex algebra, series approximations, elliptic functions, and conformal mapping were some of the principles that were developed during these two centuries. These principles eventually would be applied to derive more sophisticated forms of projection equations that would allow for more accurate mapping.

Projections developed before the 1900s predominantly used a spherical Earth model. In the 1900s some of these earlier projections were recast using the more complex ellipsoidal Earth model. This recasting was partly due to the development of reference ellipsoids in the 1800s, which provided a more accurate means of modeling Earth's size and shape compared to the spherical model. This more accurate Earth modeling resulted in maps that provided more accurate coordinate positioning, which was advantageous for topographic maps and nautical charts. Advanced mathematical principles were needed to derive the complex, ellipsoidal-based projection equations. While Albers (1805) was able to employ trigonometric functions to develop the spherical form of the projection equations for the Albers equal area conic projection, Adams (1927) later applied integral calculus in deriving the ellipsoidal form of the equations. 


\section{RECOMMENDED MAP PROJECTION CONTENT}

TABLE 3 TIES TOGETHER the results of the content analysis with the developments in projections for the purpose of recommending material that should be included in future cartography textbooks. Recommendations are grouped into eight categories, six of which were derived directly from the content analysis. The remaining two were added in recognition of the impact of recent computer technology.

In this section I review each of the categories shown in Table 3 and discuss the projection material that is recommended for future cartography textbooks. Obviously, the depth to which the material in each category is expounded upon would vary depending on the specific focus of the textbook. For example, a textbook that is more focused on thematic cartography may contain more discussion on the Map Projection Parameters or Map Projection Distortion categories, whereas a textbook focused more on web mapping may benefit from an extended discussion of material related to the Map Projections and the World Wide Web category.

\section{GEODESY}

Cartography textbooks need to expand material in the Geodesy category in three ways. First, greater emphasis needs to be placed on explaining the concept of a datum and its importance to digital data. In most mapping software, the user specifies a datum rather than a particular reference ellipsoid; the datum definition automatically couples with the associated reference ellipsoid. Second, textbooks need to discuss that a complete coordinate system definition includes a datum and projection. This discussion would include a review of common datums and map projections. Third, it is important that students realize that digital data sets commonly have unique datum assignments, and in order to bring disparate datums into a common coordinate system a transformation is needed. While datum transformations are often included in mapping software, their sheer number can be confusing (e.g., there are 34 unique datum transformation between NAD27 and WGS84 in ArcMap version 10.5). Documentation on which transformations are appropriate or even available for different datums is not readily available, which only adds to the confusion.

\section{RECOMMENDED MAP PROJECTIONS}

Weighing the decisions needed to select an appropriate projection can be challenging. The content analysis found that cartography textbooks contained a range of projection selection guidelines. Some included rudimentary guidelines while others presented more comprehensive ones. To augment the more comprehensive guidelines, I recommend that textbooks include evidence from experimental studies that offers insights, for example, into map readers' preference for overall projection shapes. I also recommend that textbooks review web resources that assist in selecting projections, such as the Projection Wizard (Šavrič, Jenny, and Jenny 2016).

\section{MATHEMATICS OF MAP PROJECTIONS}

Map projections are inherently math based, and mathematical material was consistently found in textbooks across all eras. Although the cartographer no longer calculates projections by hand, the mathematics of projections continues to play an integral role in a computer environment. To convey its importance, I offer two recommendations. First, textbooks should review the basic mathematical principles involved with projections (e.g., including worked examples of simple projection equations that demonstrate how latitude and longitude values are converted into Cartesian coordinates). Second, it is important that textbooks explain the distinction between the spherical and ellipsoidal forms of map projection equations, so that decisions can be made on when each form is appropriate for specific map purposes and map scales.

\section{MAP PROJECTION PARAMETERS}

The content analysis indicated that, beginning with the Desktop Computer Era, all textbooks included the Map Projection Parameters category. Two important points, however, were missing. First, students need to understand how to skillfully alter the default projection parameters to suit a given map purpose. To develop this skill, the specific terms presented in textbooks need to be consistent. Adopting familiar terms such as "equatorial," "oblique," and "polar" to define a projection's aspect would make it clear to the student where the geographic center of the map is located. Second, once equipped with a consistent terminology, textbooks need to convey how different projection parameters impact the distortion pattern and what 


\section{Categories}

Recommended Material

- Explain the importance of datums when using digital data

Geodesy

- Describe what constitutes a complete coordinate system definition (a datum and projection)

- Ensure students understand the importance of datum transformations

\section{Recommended}

Map Projections

\section{Mathematics of}

Map Projections

Map Projection

Parameters

Map Projection

Process

Map Projection

Distortion

Map Projections

and Programming

Languages (new)

Map Projections and the World

Wide Web (new)

- Explain that map readers have preferences for overall projection shapes

- Ensure students understand that different symbolization methods can require certain projection properties

- Utilize web-based interactive map projection selection guidelines to help students in selecting projections

- Discuss that projections are inherently mathematical and present basic mathematical principles involved

- Introduce the distinction between spherical and ellipsoidal forms of projection equations

- Explain the appropriateness of the ellipsoidal and spherical form for different map purposes

- Employ a consistent use of projection terminology

- Provide knowledge on how to skillfully alter the default projection parameters and teach the impact that those parameters have on a map

- Recognize that the light-and-shadow and developable surface concepts may be cognitively challenging for some students to master

- Interactively use software or web-based applications to teach the role that mathematics plays

- Demonstrate how different graticule arrangements result from the projection process

- Explain how the projection process acts on raster data

- Use cues from the graticule to explain distortion patterns

- Explain that map readers possess mental maps that are adaptable to viewing different projections-they are not all cast on the Mercator projection

- Show a student how to use cues taken from the projection to understand distortion patterns on a map

- Demonstrate that projections fundamentally alter how spherical rules (e.g., great circles appearing as "straight" lines on a globe) appear on a map

- Introduce programming languages (JavaScript) and code libraries (e.g., PROJ.4 and JMPL) that are useful for projections in a digital environment

- Explain how map tiles are served in a mapping service

- Describe the challenges of projecting raster data

- Discuss selecting projections for mapping services

Table 3. The eight categories reported in the content analysis and the recommended map projection material associated with each category. 
that pattern means for the final map. Many projections only have one parameter (e.g., specifying the central meridian) while others have more (e.g., the Albers equal area conic has four: central meridian, two standard lines, and the central latitude). Textbooks should clearly provide examples showing how altering these parameters impacts the distortion pattern and the appearance of the landmasses.

\section{MAP PROJECTION PROCESS}

While the mechanics of the map projection process are no longer painstakingly carried out by hand as was done in the Pre-Computer Era, textbooks need to conceptually relate how a projection utilizes latitude and longitude values to create a map. The content analysis showed that the Map Projection Process category included many different graphic and mnemonic methods used to convey this difficult concept. One commonly used method is the idea of a light source and associated shadows cast on a cone, cylinder, and plane as intermediary developable surfaces between the globe and map. The research reported by Downs and Liben (1991), however, suggested that using the light-and-shadows in concert with developable surfaces is not necessarily well-matched to the cognitive abilities of all students. One alternative model would be to use mathematical equations to show how latitude and longitude coordinates are entered into simple projection equations and then projected. By reviewing a few projection equations and which parameters are available, the student would begin to learn the individual parameters of an equation and the utility that these parameters have.

None of the projection material in the textbooks surveyed discussed how the projection process operates on raster data, which is not subjected to the same considerations as vector data when being projected. For example, as Usery and Seong (2001) report, projecting raster data produces considerable error based on the chosen projection, raster pixel size, and latitude of the location being projected. Yet, in the web environment, raster map tiles are subject to projection in web mapping services.

\section{MAP PROJECTION DISTORTION}

Distortion is an inherent consequence of the projection process. While all of the textbooks in the study included some discussion of distortion, I believe that future textbooks must address two considerations related to distortion. First, they should demonstrate the impact that distortion has on the user's ability to complete a given task. Evidence from experimental studies suggests that map readers have different levels of understanding of distortion, which will affect their ability to interpret a map. Second, textbooks should explore different methods that help students visualize the distortion patterns that appear across a projection's surface. Given these methods, students will then be able to select one or more that they feel are useful, and are better suited to their mapping needs. Textbooks could consider adopting the approach taken by Olson (2006), who offered a solution where visual evidence from the graticule could be used as a cue to help identify general patterns of distortion. The graticule exhibits certain characteristics on the Earth's surface (e.g., parallels are equally spaced). A projection can alter those characteristics, depending on the kind of projection used, in specific ways that indicate the kind of general distortion pattern that is present on the map. For example, on a conformal projection, the spacing between parallels increases as one moves from the Equator toward the poles, indicating that there is increasing scale and area distortion.

Finally, I recommend that textbooks consider referencing interactive web-based resources that students can use to explore distortion patterns on projections, such as Flex Projector (Jenny and Patterson 2013), which is freely available. It allows students to view and explore 30 pre-existing projections (although its different options also allow an infinite number of customizable projections).

\section{NEW CATEGORY: MAP PROJECTIONS AND PROGRAMMING LANGUAGES}

A new category not revealed through the content analysis, Map Projections and Programming Languages, considers the utility of a programming language when translating projection equations into a computer environment. While most mapping software packages offer a sizeable number of projections, there may be a special map purpose for which a projection is not presently or easily available. In such cases, the user would need to be familiar with a language to write the code for that projection. Although there are many programming languages available that can be used to program projections (see Kessler et al. 2017 for a review), textbooks should make students aware of languages such as JavaScript, $\mathrm{C}++, \mathrm{R}$, or specialized projection code libraries (e.g., PROJ.4 and Java Map Projection Library [JMPL]) that can simplify the code needed to incorporate a projection in a mapping application. 
NEW CATEGORY: MAP PROJECTIONS AND THE WORLD WIDE WEB

The other new category, Map Projections and the World Wide Web, considers the diverse ways in which projections are integrated into the web. For example, the following are some intriguing web-based applications: FlexProjector (allows users to interactively design a projection), ProjectionWizard (allows users to explore selecting a projection), and Projection Viewer (allows students to learn about projection distortion). The web Mercator, one of the more frequently used projections on the web, is used to display map tiles. The tile format used by mapping services re-emphasizes the need to explain how raster data are projected and the utilitarian function that the web Mercator performs. While Battersby et al. (2014) offered that the web Mercator is "good enough" for most webbased mapping tasks they cautioned that this projection is not necessarily advantageous for the appropriate display of different geographic areas as one zooms in and out of a web map or changes the latitude of a location. These concerns were addressed by Jenny (2012), who developed the Adaptive Composite Map Projections as an alternative to the web Mercator. Rather than using one projection for all zoom levels or changes in the latitude of a location, Jenny makes use of different projections to present the geographic area of interest with lower distortion.

\section{PROJECTION KNOWLEDGE AND CARTOGRAPHERS' ROLES IN THE WORKPLACE}

The OVERARCHING PERsPeCtive that is proposed here in recommending projection material for future cartography textbooks is based on equipping cartography students with the knowledge needed to work with projections in a digital environment while understanding the impact that those projections have on the map and the map reader. Obviously, practicing cartography is different today than it was at the beginning of the 1900s. In the Pre-Computer Era, a "one-size fits all" approach to cartographic education was sufficient to prepare students with the appropriate knowledge and skills to enter the workplace. However, as technology has continued to evolve, employer expectations place new demands on what is contained within textbooks and taught in the classroom.

The workplace is no longer dominated by cartographers slumped over drafting tables drawing maps. Today, there are a variety of cartographic roles. Among others, there are print cartographers, web application developers, citizen cartographers, GIS analyst-technicians, and mapping software developers. Thus, cartography textbook authors should tailor their projection material according to the scope and audience of their textbook. Each of these roles requires not only a basic understanding of projections, but oftentimes specialized projection knowledge that allows cartographers to carry out their assigned tasks. The following discussion provides a brief summary of these example roles and integrates the material from Table 3 to recommend specific projection material for future textbooks. Figure 11 provides a summary of these recommendations.

A static cartographer compiles various data layers in a digital environment to produce a map that will be printed or displayed on screen. When choosing a projection, they

\begin{tabular}{|c|l|l|l|l|l|l|l|l|}
\cline { 2 - 7 } \multicolumn{1}{c|}{} & Geodesy & $\begin{array}{c}\text { Recommended } \\
\text { Map } \\
\text { Projections }\end{array}$ & $\begin{array}{c}\text { Mathematics } \\
\text { of Map } \\
\text { Projections }\end{array}$ & $\begin{array}{c}\text { Map } \\
\text { Projection } \\
\text { Parameters }\end{array}$ & $\begin{array}{c}\text { Map } \\
\text { Projection } \\
\text { Process }\end{array}$ & $\begin{array}{c}\text { Map } \\
\text { Projection } \\
\text { Distortion }\end{array}$ & $\begin{array}{c}\text { Map } \\
\text { Projections } \\
\text { and } \\
\text { Programming } \\
\text { Languages }\end{array}$ & $\begin{array}{c}\text { Map } \\
\text { Projections } \\
\text { and the } \\
\text { World } \\
\text { Wide Web }\end{array}$ \\
\hline $\begin{array}{c}\text { Static Cartographer } \\
\text { Web Application } \\
\text { Developer }\end{array}$ & & & & & & & & \\
\hline $\begin{array}{c}\text { Citizen Cartographer } \\
\text { GIS Analyst - } \\
\text { Technician }\end{array}$ & & & & & & & & \\
\hline $\begin{array}{c}\text { Mapping Software } \\
\text { Developer }\end{array}$ & & & & & & & & \\
\hline
\end{tabular}

Figure 11. A summary of recommended projection material according to the projection categories and the example cartographer roles. 
would need to know which projections would be suitable, understanding that symbolization methods may have certain requirements that the projection should meet. They would also likely need to be familiar with the overall projection process (e.g., understanding how it creates different arrangements of the graticule and which arrangements are advantageous to the map purpose). Knowledge of the appropriate values for the different projection parameters, and their effect on distortion patterns, would also be important, especially with medium and small scale maps. In a related sense, they would also benefit from knowing how map readers view and understand distortion on a map.

A cartographer working as a web application developer would likely be involved in creating or maintaining a web mapping service. They would need to know the advantages and disadvantages of the web Mercator as well as be comfortable in their knowledge about other projections that could be incorporated into a web environment. They would benefit from using resources associated with programming languages such as JavaScript libraries (e.g., Data Driven Documents [D3]). If they were integrating a projection other than the web Mercator, they would need to be familiar with how to choose a projection, alter its parameters, and evaluate its distortion pattern against the intended map purpose. If a desired projection didn't exist in one of the JavaScript libraries, they may have to have enough of a mathematical background to write the code for a specific projection equation.

Citizen cartographers use software or web applications to create maps, but have not had any formal education in mapmaking. They may use open source software or web applications to produce maps in either print or digital formats. The software or applications they use may have a limited number of projections that are offered or parameters that can be changed. They would need to know the advantages and limitations of recommended projections.
Once a specific projection is selected, they would likely need to alter one or more of the projection parameters to control the overall distortion pattern. They would benefit from considering the arrangement of the graticule and the impact that arrangement may have on map readers. Knowledge of a programming language may be useful to them as they may need to write the code for a projection that is not presently available. For a web-based mapping service, they may want to consider a cylindric projection other than the web Mercator to serve map tiles.

The GIS analysts-technicians are professionals who incorporate digital data in both vector and raster formats into their workflow. This workflow involves defining a coordinate system (i.e., a datum and projection) that is appropriate for the map purpose. To tailor the projection for a particular map purpose, they may need to alter one or more projection parameters, and understand how these parameters can be manipulated to minimize distortion over the mapped area.

The mapping software developer may use higher-level programming languages (e.g., $\mathrm{C}++$ ) to write the code that makes mapping tools available to the end user. They need to be familiar with common datums and their appropriate transformations. They would also need to consider which projections are suited for the software's analysis tools or the potential kinds of maps and intended purposes that may be desired by the end user. Once a set of projections has been selected, the developer could either rely on existing code libraries in a particular a programming language, or, if a desired projection is not available, they may need to translate projection equations into a programming language. To assist the end user with manipulating projection parameters, the developer would need to understand the range of possible values for each projection parameter in order to set default values.

\section{CONCLUSION}

IN THIS PAPER I HAVE PRESENTED the results of a content analysis of projection material found in a sample of 24 English-langauge cartography textbooks published during the twentieth and early twentry-first centuries. The overall goals of the content analysis were twofold. First, I wanted to see what particular projection material was presented in the textbooks published in the various eras. Second,
I wanted to see whether the projection material from the various eras reflected developments in projections associated with each era.

The content analysis demonstrated that projection content from the Characterizing the Graticule, Map Projection Classes, Map Projection Properties, and Map 
Projection Distortion categories was found in every textbook throughout the study period. Other categories, such as Geodesy and Recommended Map Projections, saw an increased presence in the textbooks from the start to the end of the study period. On the other hand, the Map Projection Process category showed a decreased presence in textbooks in the latter part of the study period. Interestingly, the Graphical Construction category disappeared from the textbooks from the 1960s onward. This disappearance can be explained by the development of computer automation, which replaced much of the manual burden that mapmakers faced during the earlier part of the study period.

Eight categories of projection information are recommended for inclusion in future cartography textbooks, six of which stemmed from the content analysis (Geodesy, Recommended Map Projections, Mathematics of Map Projections, Map Projection Parameters, Map Projection Process, and Map Projection Distortion). Two additional categories (Map Projections and Programming Languages and Map Projections and the World Wide Web) were derived from developments in projections. Knowledge contained within these categories is considered essential in helping students to learn how to successfully work with projections in a digital environment.
Cartographic education today clearly has changed since the beginning of the twentieth century. Technological advances have diversified the roles that cartographers assume in the workplace. These roles ask individuals to possess general knowledge about projections (e.g., knowing how to select a given projection for a map purpose). In addition, some roles require specific knowledge about projections (e.g., programming a projection in the JavaScript language). To that end, I recommend that the specific projection material chosen to be included in cartography textbooks should be organized as a function of the varied roles that cartographers now assume in the workplace. Some of many possible examples of these roles include static cartographer, web application developer, citizen cartographer, GIS analyst-technician, and mapping software developer. For instance, I recommend that the static cartographer be versed in projection material from Recommended Map Projections, Map Projection Parameters, Map Projection Process, and Map Projection Distortion. On the other hand, the GIS analyst-technician should be equipped with projection material from Geodesy, Recommended Map Projections, Map Projection Parameters, Map Projection Distortion, and Map Projections and the World Wide Web. By considering these varied roles, and the projection categories I have outlined in this paper, future cartography textbook authors will be better able to tailor their projection materials to the needs of a modern audience.

\section{REFERENCES}

Adams, Oscar. 1927. Tables for Albers Projection.

Washington, DC: U.S. Coast and Geodetic Survey.

Albers, Heinrich. 1805. "Beschreibung einer Neuen

Kegelprojektion.” Zach's Monatliche Correspondenz zur Beförderung der Erd-und Himmels-Kunde 12: 450-459.

Anderson, Kathleen, and Gaea Leinhardt. 2002. "Maps as Representations: Expert Novice Comparison of Projection Understanding." Cognition and Instruction 20: 283-321. doi: 10.1207/s1532690xci2003_1.

Anson, Roger, Ferjan Ormeling, and International Cartographic Association. 1993. Basic Cartography for Students and Technicians: Volume 1. London: Elsevier Science. doi: 10.1016/c2013-0-12607-4.
Battersby, Sarah, Michael Finn, E. Lynn Usery, and Kristina Yamamoto. 2014. "Implications of Web Mercator and its Use in Online Mapping." Cartographica 49: 85-101. doi: 10.3138/ carto.49.2.2313.

Battersby, Sarah, and Fritz Kessler. 2012. "Cues for Interpreting Distortion in Map Projections.” Journal of Geography 111: 93-101. doi: 10.1080/00221341.2011.609895.

Battersby, Sarah, and Daniel Montello. 2009. “Area Estimation of World Regions and the Projection of the Global-Scale Cognitive Map." Annals of the Association of American Geographers 99: 273-291. doi: 10.1080/00045600802683734. 
Bay, Helmuth. 1943. The History and Technique of Map Making. New York: The New York Public Library.

Birch, Thomas. 1964. Maps Topographical and Statistical. Oxford: Oxford University Press.

Bygott, John, and D. C. Money. 1962. An Introduction to Mapwork and Practical Geography. London: University Tutorial Press.

Campbell, John. 1984. Introductory Cartography. Englewood Cliffs, NJ: Prentice-Hall.

. 2001. Map Use and Analysis, 4th Edition. Boston: McGraw-Hill.

Chrisman, Nick. 2016. "Calculating on a Round Planet." International Journal of Geographical Information Science 31: 637-657. doi: 10.1080/13658816.2016.1215466.

Close, Charles. 1905. Text Book of Topographical and Geographical Surveying. London: Harrison and Sons.

Cuff, David, and Mark Mattson. 1982. Thematic Maps: Their Design and Production. New York: Routledge.

Dahlberg, Richard. 1991. "Shaping the World Map" In Matching the Map Projection to the Need, edited by Arthur H. Robinson and John P. Snyder, 6-7. Washington, DC: American Congress on Surveying and Mapping.

Deetz, Charles. 1936. Cartography. Washington, DC: Coast and Geodetic Survey.

Dent, Borden. 1990. Cartography: Thematic Map Design, 2nd Edition. Dubuque, IA: Brown.

Department of Defense. 1980. Glossary of Mapping, Charting, and Geodetic Terms, 4th Edition. Washington, DC: Defense Mapping Agency.

Downs, Roger, and Lynn Liben. 1991. “The Development of Expertise in Geography: A CognitiveDevelopmental Approach to Geographic Education." Annals of the Association of American Geographers 82: 304-327. doi: 10.1111/j.1467-8306.1991.tb01692.x.

Edney, Matthew. 2014. "A Content Analysis of Imago Mundi. 1935-2010.” Imago Mundi 66, Supplement: 107-131. doi: 10.1080/03085694.2014.947855.
Esri, 1991. Map Projections E Coordinate Management:

Concepts and Procedures. Redlands, CA: Environmental Systems Research Institute.

Fryman, James. 1996. "Cartographic Education in the United States and Canada.” Cartographica 33: 5-13. doi: 10.3138/L261-211K-524P-674P.

Fryman, James, and Bonnie Sines. 1990. "Anatomy of the Introductory Cartography Course." Cartographic Perspectives 8: 4-10. doi: 10.14714/cp08.1082.

1998. "Anatomy of the Introductory Cartography Course Revisited." Cartographic Perspectives 30: 6-17. doi: 10.14714/cp30.660.

Gilmartin, Patricia. 1992. "Twenty-Five Years of Cartographic Research: A Content Analysis." Cartography and Geographic Information Science 19: 37-47. doi: 10.1559/152304092783786645.

Gluck, Michael. 1998. "Content Analysis, Semiotics, and Social Semiotics for Cartographic Analysis: Interpreting Geospatial Representations." Cartographic Perspectives 31: 4-25. doi: 10.14714/cp31.647.

Greenhood, David. 1951. Down to Earth: Mapping for Everybody. New York: Holiday House.

Jenny, Bernhard. 2012. "Adaptive Composite Map Projections." IEEE Transactions on Visualization and Computer Graphics. 18: 2575-2582. doi: 10.1109/ tvcg.2012.192.

Jenny, Bernhard, and Tom Patterson. 2013. "Blending World Map Projections with Flex Projector.” Cartography and Geographic Information Science 40: 289-296. doi: 10.1080/15230406.2013.795002.

Jervis, Walter. 1937. The World in Maps. A Study in Map Evolution. London: Oxford University Press.

Kessler, Fritz, Sarah Battersby, Michael Finn, and Keith Clarke. 2017. “Map Projections and the Internet.” In Choosing a Map Projection, edited by Miljenko Lapaine and E. Lynn Usery, 117-148. Cham, Switzerland: Springer. 
Kessler, Fritz, and Terry Slocum. 2011. "Analysis of Thematic Maps Published in Two Geographical Journals in the Twentieth Century." Annals of the Association of American Geographers 101(2): 292-317. doi: 10.1080/00045608.2010.544947.

Kraak, Menno-Jan, and Ferjan Ormeling. 2010. Cartography: Visualization of Spatial Data, 3rd Edition. New York: Guilford Press.

Krippendorf, Klaus. 2019. Content Analysis: An Introduction to its Methodology, 4th Edition. Thousand Oaks, CA: SAGE Publications.

Lapaine, M., Tutić, D., and Triplat, H. M. 2014. "Visualization of Deformations in Cylindrical Map Projections," 5th Croatian Conference on Cadaster, Croatian Geodetic Society, May 8-9, 2014, Zagreb, Croatia. http://ica-proj.kartografija.hr/tl_files/ ICA\%20Map\%20Projections\%20Commission/slike/ cilindricne_final_en.xml.

Lawrence, George. 1971. Cartographic Methods. London: Methuen.

Lee, Laurence. 1965. "Some Conformal Projections Based on Elliptic Functions." Geographical Review, 55: 563-580. doi: 10.2307/212415.

Monmonier, Mark, and Michael Gluck. 1994. "Focus Groups for Design Improvement in Dynamic Cartography." Cartography and Geographic Information Systems 21: 37-47. doi: 10.1559/152304094782563948.

Montello, Daniel. 2002. “Cognitive Map-Design Research in the Twentieth Century: Theoretical and Empirical Approaches." Cartography and Geographic Information Science 29: 283-304. doi: $10.1559 / 152304002782008503$.

Morrison, James. 1902. Maps, Their Uses and Construction: A Short Popular Treatise on the Advantages and Defects of Maps on Various Projections Followed by an Outline of the Principles Involved in Their Construction. London: Edward Stanton.

Muehlenhaus, Ian. 2011. "Another Goode Method: How to Use Quantitative Content Analysis to Study Variations in Thematic Map Design." Cartographic Perspectives 69: 7-29. doi: 10.14714/cp69.28.
2013. "The Design and Composition of

Persuasive Maps." Cartography and Geographic Information Science 40: 401-414. doi: 10.1080/15230406.2013.783450.

Muehrcke, Phillip, and Juliana Muehrcke. 1978. Map Use: Reading, Analysis, and Interpretation. Madison, WI: JP Publications.

Mulcahy, Karen, and Keith Clarke. 2001. "Symbolization of Map Projection Distortion: A Review." Cartography and Geographic Information Science 28: 167-182. doi: 10.1559/152304001782153044.

Olson, Judy. 2006. "Map Projections and the Visual Detective: How to Tell if a Map is Equal-Area, Conformal, or Neither." Journal of Geography 105: 13-32. doi: 10.1080/00221340608978655.

Raisz, Erwin. 1938. General Cartography. New York: McGraw-Hill.

. 1948. General Cartography, 2nd Edition. New
York: McGraw-Hill.

Reeves, Edward. 1910. Maps and Map-Making: Three Lectures Delivered Under the Auspices of the Royal Geographical Society. London: Royal Geographical Society.

Roberts, Lawrence. 1924. Topographic Mapping. Washington, DC: Society of American Military Engineers.

Robinson, Arthur. 1952. The Look of Maps. Madison, WI: University of Wisconsin Press.

1953. Elements of Cartography. New York: John
Wiley \& Sons. Šavrič, Bojan, Bernhard Jenny, and Helen Jenny. 2016. "Projection Wizard - An Online Map Projection Selection Tool." The Cartographic Journal 53: 177-185. doi: 10.1080/00087041.2015.1131938.

Šavrič, Bojan, Bernhard Jenny, Dennis White, and Daniel Strebe. 2015. "User Preferences for World Map Projections." Cartography and Geographic Information Science 42: 398-409. doi: 10.1080/15230406.2015.1014425. 
Schreier, Margrit. 2012. Qualitative Content Analysis in Practice. Thousand Oaks, CA: SAGE Publications.

Slocum, Terry, Robert McMaster, Fritz Kessler, and Hugh Howard. 2005. Thematic Cartography and Geovisualization, 2nd edition. Upper Saddle River, NJ: Prentice Hall.

Slocum, Terry, and Fritz Kessler. 2015. "Thematic Mapping." In History of Cartography Volume 6: Cartography in the Twentieth Century, edited by Mark Monmonier, 1500-1525. Chicago: University of Chicago Press.

Snyder, John. 1985. Map Projections: A Working Manual. United States Geological Survey. Washington, DC: U.S. Government Printing Office.

1993. Flattening the Earth: Two-Thousand Years of Map Projections. Chicago: University of Chicago Press.
Tissot, Nicholas. 1859. "Sur les Cartes Géographiques." Comptes Rendus des Séances de L'Académies des Sciences 49: 673-679.

Tyner, Judith. 2014. Principles of Map Design, 2nd Edition. New York: The Guilford Press.

Usery, E. Lynn, and Jeong Seong. 2001. "All EqualArea Map Projections Are Created Equal, but Some Are More Equal Than Others." Cartography and Geographic Information Science 28: 183-193. doi: $10.1559 / 152304001782153053$.

Werner, Robert. 1993. "A Survey of Preference Among Nine Equator-Centered Map Projections." Cartography and Geographic Information Systems 20: 31-39. doi: 10.1559/152304093782616733.

Wilson, Herbert. 1912. Topographic, Trigonometric and Geodetic Surveying: Including Geographic, Exploratory, and Military Mapping, with Hints on Camping, Emergency Surgery, and Photography. New York: J. Wiley \& Sons. 


\begin{tabular}{|c|c|c|c|}
\hline Decade & Textbook Title and Edition & Author(s) & $\begin{array}{l}\text { Publication } \\
\text { Date }\end{array}$ \\
\hline \multirow{4}{*}{1900} & Maps, Their Uses and Construction & G. James Morrison & 1902 \\
\hline & $\begin{array}{l}\text { Text Book of Topographical and Geographical } \\
\text { Surveying }\end{array}$ & Charles Close & 1905 \\
\hline & Mathematical Geography & Willis Johnson & 1907 \\
\hline & Practical Geography & Frederick Mort & 1908 \\
\hline \multirow{4}{*}{1910} & Maps and Map Making & Edward Reeves & 1910 \\
\hline & $\begin{array}{l}\text { Topographic, Trigonometric and Geodetic Surveying, } \\
\text { Including Geographic, Exploratory, and Military } \\
\text { Mapping with Hints on Camping, Emergency Surgery, } \\
\text { and Photography }\end{array}$ & Herbert Wilson & 1912 \\
\hline & Handbook of Geography: Descriptive \& Mathematical & Eml Reich & 1918 \\
\hline & Map Reading and Topographical Sketching & Edwin Stuart & 1918 \\
\hline \multirow{4}{*}{1920} & Maps and Surveys (2nd edition) & Arthur Hinks & 1923 \\
\hline & Topographic Mapping & Lawrence Roberts & 1924 \\
\hline & Maps: How they are made; how to read them & Henry Dickson & 1926 \\
\hline & Mathematical Geography & Alexander Jameson and Michael Ormsby & 1927 \\
\hline \multirow{4}{*}{1930} & Drafting and surveying course & U.S. Army Engineering School & 1930 \\
\hline & Map Drafting and Lettering & Howard Saunders and Howard lves & 1931 \\
\hline & Cartography & Charles Deetz & 1936 \\
\hline & The World in Maps: A Study in Evolution & Walter Jervis & 1937 \\
\hline \multirow{4}{*}{1940} & The History and Technique of Map Making & Helmuth Bay & 1943 \\
\hline & Cartography, Map Making & Hubert Bauer & 1945 \\
\hline & General Cartography (2nd edition) & Erwin Raisz & 1948 \\
\hline & Advanced Surveying and Mapping & George Whitmore & 1949 \\
\hline
\end{tabular}




\begin{tabular}{|c|c|c|c|}
\hline Decade & Textbook Title and Edition & Author(s) & $\begin{array}{l}\text { Publication } \\
\text { Date }\end{array}$ \\
\hline \multirow{4}{*}{1950} & Down to Earth: Mapping for Everybody & David Greenhood & 1951 \\
\hline & Elements of Cartography & Arthur Robinson & 1953 \\
\hline & A Guide to the Compilation and Revision of Maps & Department of the Army & 1955 \\
\hline & Mathematical Cartography & Aleksei Graur & 1956 \\
\hline \multirow{4}{*}{1960} & Principles of Cartography & Erwin Raisz & 1962 \\
\hline & An Introduction to Mapwork and Practical Geography & John Bygott and D. C. Money & 1962 \\
\hline & Maps: Topographical and Statistical & Thomas Birch & 1964 \\
\hline & Cartography & Robert Maxwell & 1964 \\
\hline \multirow{4}{*}{1970} & Cartographic Methods & George Lawrence & 1971 \\
\hline & Cartographic Design and Production & John Keates & 1973 \\
\hline & Maps and Map Making & Robert Duru & 1977 \\
\hline & Map Use: Reading, Analysis, and Interpretation & Phillip Muehrcke and Juliana Muehrcke & 1978 \\
\hline \multirow{4}{*}{1980} & Thematic Map Design & David Cuff and Mark Mattson & 1982 \\
\hline & Basic Cartography for Students and Teachers & Roger Anson and Ferjan Ormeling & 1984 \\
\hline & Basic Graphics and Cartography & Claude Westfall & 1984 \\
\hline & Principles of Thematic Map Design & Borden Dent & 1985 \\
\hline \multirow{4}{*}{1990} & Cartography: Thematic Map Design (2 $2^{\text {nd }}$ edition) & Borden Dent & 1990 \\
\hline & Introductory Cartography & John Campbell & 1991 \\
\hline & $\begin{array}{l}\text { Mapping it Out: Expository Cartography for the } \\
\text { Humanities and Social Sciences }\end{array}$ & Mark Monmonier & 1993 \\
\hline & Mapping: Ways of Representing the World & Daniel Dorling and David Fairbairn & 1997 \\
\hline
\end{tabular}




\begin{tabular}{|c|c|c|c|}
\hline Decade & Textbook Title and Edition & Author(s) & $\begin{array}{l}\text { Publication } \\
\text { Date }\end{array}$ \\
\hline \multirow{4}{*}{2000} & Map Use and Analysis (5th edition) & John Campbell & 2005 \\
\hline & Thematic Cartography and Geovisualization (2 ${ }^{\text {nd }}$ edition) & $\begin{array}{l}\text { Terry Slocum, Bob McMaster, Fritz Kessler, } \\
\text { and Hugh Howard }\end{array}$ & 2005 \\
\hline & Cartography: an Introduction & Mary Spence and Giles Darkes & 2008 \\
\hline & GIS Cartography & Gretchen Peterson & 2009 \\
\hline \multirow{4}{*}{2010} & $\begin{array}{l}\text { Cartography and Visualization of Spatial Data }\left(3^{\text {rd }}\right. \\
\text { edition) }\end{array}$ & Menno-Jan Kraak and Ferjan Ormeling & 2010 \\
\hline & Making Maps: A Visual Guide to Map Design for GIS & John Krygier and Denis Wood & 2011 \\
\hline & Principles of Map Design (2 $2^{\text {nd }}$ edition) & Judith Tyner & 2014 \\
\hline & Map Use: Reading, Analysis, Interpretation & $\begin{array}{l}\text { Jon Kimerling, Juliana Muehrcke, Aileen } \\
\text { Buckley, and Phillip Muehrcke }\end{array}$ & 2016 \\
\hline
\end{tabular}

